\title{
Evaluación del poder inhibitorio de extractos obtenidos de plantas medicinales sobre enterobacterias patógenas de importancia en Salud Pública
}

\author{
Evaluation of the inhibitory power of extracts obtained from medicinal \\ plants on on pathogenic enterobacteria relevant in public health
}

\author{
Fernández Mijail ${ }^{1,2,4}$, Silva Piero',2,4, Costa Magdalena ${ }^{2,3}$ (i) , Galli Lucía ${ }^{2,3}$ (i) , \\ BRUNO ESTELA ${ }^{2,4}, *$
}

1. Facultad de Ciencias Farmacéuticas, Bioquímicas y Biotecnológicas, Arequipa-Arequipa, Perú. 2. Cátedra Microbiología Aplicada, Facultad de Ciencias Veterinarias (FCV), Universidad Nacional de La Plata (UNLP), Argentina. 3. Consejo Nacional de Investigaciones Científicas y Técnicas (CONICET), Argentina. 4. Centro de Investigación y Desarrollo en Criotecnología de Alimentos (CIDCA, UNLP-CONICET-CICPBA), Argentina.

* Correo electrónico de la autora de contacto: ebruno@fcv.unlp.edu.ar

\begin{abstract}
Resumen
Los extractos vegetales pueden ser obtenidos de diferentes partes de las plantas como hojas, tallos, flores y raíces. El interés por los extractos vegetales ha aumentado notablemente por sus propiedades bactericidas, fungicidas y antioxidantes. Por tal motivo, el objetivo del presente trabajo consistió en evaluar el poder inhibitorio de sustancias extraídas de cuatro plantas medicinales: Schinus molle (molle), Sesamum indicum (sésamo) Cinnamomum zeylanicum (canela) y Minthostachys mollis (muña) frente a diez bacterias enterobacterias patógenas. Los extractos se obtuvieron con o sin maceración empleando solventes orgánicos y por extracción acuosa. La metodología de extracción que presentó mayor poder inhibitorio fue la realizada con solventes orgánicos, mientras que las extracciones acuosas fueron las que presentaron un poder menor. En los ensayos de inhibición, el extracto de canela fue el que presentó mayor poder inhibitorio frente a los enterobacterias patógenas, mientras que la combinación de canela con sésamo (1:1) mostró un efecto sinérgico, potenciando la actividad antibacteriana. Además, la canela presentó actividad bactericida frente a Salmonella ser. typhimurium y Salmonella ser. enteritidis.
\end{abstract}

\section{Palabras clave}

Plantas medicinales, extractos vegetales, inhibición, enterobacterias patógenas

\begin{abstract}
Vegetable extracts can be obtained from different parts of plants such as leaves, stems, flowers and roots. Interest in vegetable extracts has increased significantly due to their bactericidal, fungicidal and antioxidant properties. For this reason, the objective of this work was to evaluate the inhibitory power of the vegetable substances extracted from four medicinal plants: Schinus molle (molle), Sesamum indicum (sesame) Cinnamomum zeylanicum (cinnamon) and Minthostachys mollis (muña) against ten pathogenic enterobacteria. The extracts were obtained with or without maceration with organic solvents and by aqueous extraction. The extraction methodology that presented the highest inhibitory power was that carried out with organic solvents, while the aqueous extractions were those that presented lower inhibitory power. In the inhibition assays, cinnamon extract showed the greatest inhibitory power against pathogenic enterobacteria, while the cinnamon extract combined with sesame (1:1) showed a synergistic effect enhancing antibacterial activity. In addition, cinnamon presented bactericidal effect against Salmonella ser. typhimurium and Salmonella ser. enteritidis.
\end{abstract}

\section{Key words}

Medicinal plants, vegetable extracts, inhibition, pathogenic enterobacteria

Fecha de recepción: 03/05/2019

Fecha de revisión: 19/07/2019

Fecha de aprobación: 26/09/2019
Analecta Vet 2019; Julio-Diciembre; 39(2):27-32

Impresa ISSN 03655 14-8 Electrónica ISSN 1514-2590

doi.org/10.24215/15142590e040 


\section{Introducción}

Los productos alimenticios están frecuentemente propensos a la contaminación causada por agentes patógenos. Con el fin de garantizar la seguridad alimentaria, existe la necesidad de generar medidas de control eficaces con conservantes antimicrobianos, que garanticen la inactivación bacteriana y que a su vez no generen efectos secundarios por su consumo. Por tal motivo, se están estudiando extractos vegetales con la finalidad de demostrar su capacidad antimicrobiana (García et al., 2010). Los extractos son mezclas de varias sustancias químicas biosintetizadas por las plantas y están compuestos principalmente por terpenos y sus derivados, así como también, hidrocarburos, alcoholes, ácidos, ésteres, y aldehídos. Tienen un amplio campo de aplicación tanto para medicina humana como veterinaria (Abadie et al., 2014; Bozin et al., 2006; Deveci et al., 2010).

Las características de las plantas medicinales tales como Sesamum indicum (sésamo), Cinnamomum zeylanicum (canela), Minthostachys mollis (muña), Schinus molle (molle), son las siguientes: el extracto de sésamo está compuesto principalmente por sesamina y sesamolina, por lo que los usos son alimentario, medicinal, antioxidante y bactericida (Castro Montoya et al., 2015). El extracto de canela está compuesto principalmente por sustancias antioxidantes fenólicas y polifenólicas (Sánchez Miranda, 2013) y además contiene cinamaldehído como principio activo. Se utiliza en la industria alimentaria y medicinal como antibacteriano y antifúngico (Wong et al., 2014). El extracto de muña está compuesto principalmente por sustancias terpénicas y fenilpropánicas. Se utiliza en la industria alimentaria como digestivo, antihelmíntico, afrodisíaco y antibacteriano y en la industria farmacéutica como antifúngico y antibacteriano (Alegre et al., 2017). El molle está compuesto mayoritariamente por terpenos (Arias et al., 2017). Sus múltiples usos abarcan aspectos químicos, industriales, médicos $\mathrm{y}$ alimenticios.

El objetivo del presente trabajo consistió en evaluar y comparar el poder inhibitorio de los extractos de plantas medicinales: Schinus molle (molle), Sesamum indicum (sésamo) Cinnamomum zeylanicum (canela) y Minthostachys mollis (muña) sobre diez enterobacterias patógenas de importancia en la Salud Pública, algunos con probada capacidad zoonótica.

\section{Materiales y métodos}

\section{Obtención de extractos vegetales}

La materia prima utilizada para obtener los extractos vegetales se adquirió en el Mercado Andino de Liniers (Buenos Aires, Argentina), en febrero de 2018. Las ramas y hojas de las plantas se lavaron 4 veces con agua potable, se sumergieron durante 5 min en hipoclorito de sodio al $10 \%$, se filtraron, se enjuagaron con agua destilada estéril y se secaron en estufa. Posteriormente se trituraron (multiprocesadora Peabody, PEMC9103, China). Para la obtención de los extractos acuosos, se colocaron $4 \mathrm{~g}$ de muestra en $36 \mathrm{~mL}$ de agua destilada, se sometieron a agitación durante $30 \mathrm{~min}$, y se centrifugaron a $6000 \mathrm{rpm}$, a $4{ }^{\circ} \mathrm{C}$, durante 10 min (Darré et al., 2017). Posteriormente, se retiró el sobrenadante y se reservó. El pellet resultante de esta primera extracción se resuspendió con $18 \mathrm{ml}$ de agua destilada y se procesó repitiendo el procedimiento anteriormente descripto. El sobrenadante obtenido de esta segunda extracción se combinó con el de la primera extracción y se conservó a $\mathrm{o}^{\circ} \mathrm{C}$ durante 24 h. La conservación de este extracto se realizó liofilizando el sobrenadante obtenido en la primera y segunda extracción.

Para la obtención de los extractos con solventes orgánicos se procedió según la metodología de Darré et al., (2017), agregando $36 \mathrm{ml}$ de metanol absoluto o etanol $96^{\circ}$ a $4 \mathrm{~g}$ de muestra. Para analizar el efecto del tiempo de extracción, un lote de extractos se utilizó para realizar las determinaciones inmediatamente, mientras que el otro lote se dejó macerar 7 días a ${ }^{\circ}{ }^{\circ} \mathrm{C}$ para luego realizar las determinaciones. Posteriormente, los lotes se centrifugaron a $6000 \mathrm{rpm}$, a $4{ }^{\circ} \mathrm{C}$, durante $10 \mathrm{~min}$. El sobrenadante fue retirado y se concentró por medio de un rotavapor (Büchi R124, Labortechnik A.G., Flawil, Suiza).

\section{Ensayos de inhibición de las enterobac- terias patógenas}

\subsection{Método de difusión en agar por disco}

Para los ensayos de inhibición se utilizaron 10 cepas bacterianas de la colección del Laboratorio de Seguridad Alimentaria perteneciente a la Facultad de Ciencias Veterinarias de la Universidad Nacional de la Plata (Tabla 1). Los ensayos de inhibición se realizaron según la metodología descripta por Shiva Ramayoni (2007). Brevemente, las cepas se cultivaron en caldo nutritivo durante $18-24 \mathrm{~h}$ a $37{ }^{\circ} \mathrm{C}$ y su densidad óptica fue estandarizada utilizando el equipo DEN-1B (Biosan, Biosystem, Argentina) alcanzando un valor equivalente a $108 \mathrm{UFC} / \mathrm{ml}$. Cada uno de los microorganismos se sembró con hisopos estériles en placas de agar nutritivo (Britania, Argentina) en forma de pátina. Los extractos se utilizaron en forma individual y combinados: molle, canela, muña, sésamo, molle + sésamo, canela + sésamo. Los extractos acuosos liofilizados se resuspendieron en agua destilada hasta una concentración del $10 \%$ de cada uno de los rendimientos obtenidos, mientras que los obtenidos con solventes orgánicos se utilizaron puros después de la utilización del rotavapor. Para el ensayo de difusión se embebieron discos de 
Inhibición de enterobacterias por extractos vegetales

Tabla 1. Enterobacterias patógenas utilizadas para los ensayos de inhibición bacteriana

\begin{tabular}{|c|c|c|c|c|}
\hline Microorganismo & Identificación & Serotipo/Serovar & $\begin{array}{c}\text { Caracterización } \\
\text { genotípica }\end{array}$ & Origen \\
\hline $\begin{array}{l}\text { Escherichia coli enteroagregativa } \\
\text { (EAEC) }\end{array}$ & L12 & & aggR & caso clínico \\
\hline Escherichia coli enteroinvasiva (EIEC) & L14 & & $i p a \mathrm{H}$ & caso clínico \\
\hline $\begin{array}{l}\text { Escherichia coli enterotoxigénica } \\
\text { (ETEC) }\end{array}$ & L22 & & lt/st & caso clinico \\
\hline $\begin{array}{l}\text { Staphylococcus aureus } \\
\text { Shigella flexneri }\end{array}$ & $\begin{array}{l}\mathrm{L} 290 \\
\mathrm{~L} 392\end{array}$ & & sea & alimentos \\
\hline $\begin{array}{l}\text { Shigella lexnert } \\
\text { Escherichia coli }\end{array}$ & $\begin{array}{l}\text { L592 } \\
\text { L564 }\end{array}$ & $\mathrm{O} 157: \mathrm{H} 7$ & $s t x_{2} / f l i C_{\mathrm{H} 7} / r f b_{0157}$ & carne picada \\
\hline $\begin{array}{l}\text { Escherichia coli productora de toxina } \\
\text { Shiga (STEC) }\end{array}$ & L1046 & $\mathrm{O} 26: \mathrm{H} 11$ & $s t x_{1} / s t x_{2}$ & carne picada \\
\hline $\begin{array}{l}\text { Escherichia coli enteropatógena (EPEC) } \\
\text { Salmonella }\end{array}$ & $\begin{array}{l}\mathrm{L} 1122 \\
\mathrm{~L} 1492\end{array}$ & $\begin{array}{l}\text { O177:H11 } \\
\text { enteritidis }\end{array}$ & eae & carne bovina \\
\hline $\begin{array}{l}\text { Salmonella } \\
\text { Salmonella }\end{array}$ & $\begin{array}{l}L 1492 \\
\text { L1570 }\end{array}$ & $\begin{array}{l}\text { enteritidis } \\
\text { typhimurium }\end{array}$ & & $\begin{array}{l}\text { carne picada } \\
\text { carne de } \\
\text { frigorifico }\end{array}$ \\
\hline
\end{tabular}

papel de filtro (Whatman $\AA$ 91, wet strengthened qualitative, Maidstone, England) de $4 \mathrm{~mm}$ de diámetro a saturación, colocando no más de cuatro discos por placa (Figura 1). Los ensayos se realizaron por duplicado. La medición del poder inhibitorio antibacteriano se determinó cualitativamente mediante la formación de halos de inhibición, los que se clasificaron en dos categorías: inhibitorio (+) y no inhibitorio (-).

\subsection{Determinación de actividad bacterios- tática/bactericida de los extractos vege- tales}

Los extractos vegetales y las cepas que en el ensayo de inhibición por difusión en agar presentaron halos de inhibición bacteriana, se utilizaron para el ensayo de la actividad bactericida/ bacteriostática según Henao Riveros (2003). Brevemente, en un tubo de ensayo estéril se colocaron $5 \mathrm{ml}$ del extracto puro a ensayar (metanólico, etanólico) y se agregaron $0,5 \mathrm{ml}$ de un cultivo puro de cada enterobacteria. El momento que se mezcla el extracto puro con el microorganismo se considera como tiempo o $\left(t_{0}\right)$. En to, a 2,5, 5 y $10 \mathrm{~min}$, se transfirieron dos ansadas a tubos con $5 \mathrm{ml}$ de caldo nutritivo (Britania, Argentina) y luego se incubaron durante $24 \mathrm{~h}$ a $37^{\circ} \mathrm{C}$. En los tubos en los que se observó un crecimiento microbiano (+) en los diferentes tiempos, pero no en el inicial to, los extractos fueron considerados bacteriostáticos. En los tubos en los que no se observó desarrollo microbiano (-), los extractos fueron considerados bactericidas.

\section{Resultados y discusión}

Los extractos de condimentos y especias se han estudiado desde el punto de vista funcional, si tienen actividad antimicrobiana, si actúan como agentes antioxidantes o si aportan nutrientes. Las propiedades funcionales de los extractos varían con la proporción de los compuestos presentes. Para especias diferentes se obtienen respuestas diferentes en su actividad antimicrobiana de acuerdo a las condiciones en las que se procesan (Peredo-Luna et al., 2009). Las muestras extraídas en este trabajo con solventes orgánicos, maceradas y concentradas con el uso del rotavapor, mostraron poder inhibitorio, no así los extractos etanólicos y metanólicos sin maceración, ni los acuosos, con excepción del extracto acuoso de canela sobre la cepa de Staphylococcus aureus (Tabla 2). Este resultado puede explicarse teniendo en cuenta que, para extraer los principios activos con actividad antibacteriana, el solvente debe penetrar y disolverlos. En cambio, los extractos acuosos no se maceran, ya que pueden propiciar la fermentación o la formación de mohos (González Villa, 2004). Herrera Arias y García-Rico (2006) también demostraron que los extractos acuosos de canela tuvieron un efecto inhibitorio sobre el crecimiento de la cepa de $S$. aureus. Sin embargo, a diferencia de los resultados obtenidos por los autores antes mencionados, las cepas de $E$. coli y Salmonella spp. utilizadas en el presente trabajo no fueron sensibles al extracto de canela, lo que estaría indicando que el poder inhibitorio es específico de variedad de especie, siendo las utilizadas en este trabajo cepas autóctonas.

Los extractos etanólicos presentaron poder inhibitorio solo frente a la cepa de $S$. aureus. Estos resultados coinciden con los hallados por Burt (2004), siendo los organismos gram[+] ligeramente más sensibles que los gram[-].

Los resultados más efectivos se obtuvieron a partir de los extractos vegetales obtenidos con metanol. El molle inhibió el desarrollo de $S$. aureus. La canela inhibió a $S$. aureus, Escherichia coli $\mathrm{O} 157: \mathrm{H} 7, E$. coli productor de toxina Shiga (STEC), E. coli enteropatógeno (EPEC), Salmonella ser. enteritidis y $S$. ser. typhimurium. La muña inhibió a $S$. aureus. El sésamo no inhibió a ninguna de los enterobacterias ensayadas. 
Tabla 2. Ensayo de inhibición de los extractos vegetales sobre las enterobacterias patógenas

\begin{tabular}{|c|c|c|c|c|c|c|c|c|c|c|c|c|c|c|c|c|c|c|}
\hline \multirow[t]{2}{*}{ Microorganismo } & \multicolumn{3}{|c|}{ molle } & \multicolumn{3}{|c|}{ canela } & \multicolumn{3}{|c|}{ muña } & \multicolumn{3}{|c|}{ sésamo } & \multicolumn{3}{|c|}{$\begin{array}{c}\text { sésamo } \\
\text { molle }\end{array}$} & \multicolumn{3}{|c|}{$\begin{array}{c}\text { sésamo + } \\
\text { canela }\end{array}$} \\
\hline & $\mathrm{A}$ & $E$ & $\mathrm{M}$ & $\mathrm{A}$ & $E$ & $\mathrm{M}$ & $\mathrm{A}$ & $E$ & $\mathrm{M}$ & $\mathrm{A}$ & $\mathrm{E}$ & $\mathrm{M}$ & $\mathrm{A}$ & $E$ & $\mathrm{M}$ & $\mathrm{A}$ & $E$ & $\mathrm{M}$ \\
\hline E. coli (EAEC) & - & - & - & - & - & - & - & - & - & - & - & - & - & - & - & - & - & + \\
\hline E. coli (EIEC) & - & - & - & - & - & - & - & - & - & - & - & - & - & - & - & - & - & + \\
\hline E. coli (ETEC) & - & - & - & - & - & - & - & - & - & - & - & - & - & - & - & - & - & + \\
\hline S. aureus & - & + & + & + & + & + & - & + & + & - & - & - & - & + & + & - & + & + \\
\hline S. flexneri & - & - & - & - & - & - & - & - & - & - & - & - & - & - & - & - & - & + \\
\hline E. coli $(\mathrm{O} 157)$ & - & - & - & - & - & + & - & - & - & - & - & - & - & - & - & - & - & + \\
\hline E. coli (STEC) & - & - & - & - & - & + & - & - & - & - & - & - & - & - & - & - & - & + \\
\hline E. coli (EPEC) & - & - & - & - & - & + & - & - & - & - & - & - & - & - & - & - & - & + \\
\hline$S$. ser. enteritidis & - & - & - & - & - & + & - & - & - & - & - & - & - & - & - & - & - & + \\
\hline$S$. ser. typhimurium & - & - & - & - & - & + & - & - & - & - & - & - & - & - & - & - & - & + \\
\hline
\end{tabular}

A: extracción acuosa; E: extracción etanólica con maceración; M: extracción metanólica con maceración

En la literatura se registran numerosas combinaciones de extractos vegetales para potenciar su actividad, como la canela más el clavo de olor (Pastrana Puche et al., 2017). En el presente trabajo, la combinación del sésamo con el molle produjo inhibición de $S$. aureus, mientras que la combinación del sésamo con la canela inhibió el desarrollo de todas las cepas ensayadas. Asimismo, estudios anteriores como los de Amara et al., (2008) y Huamán et al., (2003) demostraron la actividad antibacteriana del extracto metanólico de la canela (que en este trabajo fueron preparados a partir de la corteza).

La evaluación del efecto bacteriostático/ bactericida puede observarse en la Tabla 3. La mayoría de los extractos ensayados presentaron efecto bacteriostático a $t_{0}$, mientras que el efecto bactericida solo se observó en la canela frente a $S$. ser. typhimurium a 5 min y frente a $E$. coli O157:H7 a 10 min. Los extractos de molle, molle + sésamo y muña frente a $S$. aureus no presentaron ningún tipo de efecto. Esto puede relacionarse con lo descripto por diversos investigadores que han demostrado que se requieren altas concentraciones de principios activos de extractos vegetales para lograr inhibir el crecimiento de microorganismos patógenos (Rodríguez Pava et al., 2017).

En la literatura se registran numerosas combinaciones de extractos vegetales para potenciar su actividad, como la canela más el clavo de olor (Pastrana Puche et al., 2017). En el presente trabajo, la combinación del sésamo con el molle produjo inhibición de $S$. aureus, mientras que la combinación del sésamo con la canela inhibió el desarrollo de todas las cepas ensayadas. Asimismo, estudios anteriores como los de Amara et al., (2008) y Huamán et al., (2003) demostraron la actividad antibacteriana del extracto metanólico de la corteza de canela.

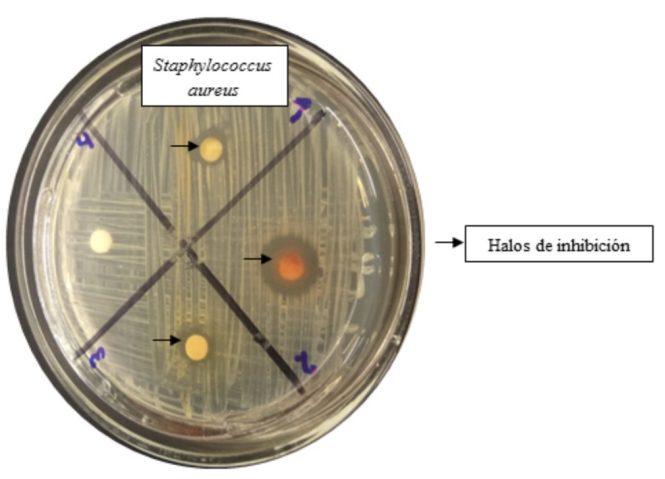

Figura 1. Poder inhibitorio de extractos vegetales sobre el Staphylococcus aureus. Método de difusión en agar nutritivo por disco frente a molle (1), canela (2), muña (3), sésamo (4). La flecha indica los halos de inhibición.

La evaluación del efecto bacteriostático/ bactericida puede observarse en la Tabla 3. La mayoría de los extractos ensayados presentaron efecto bacteriostático a to, mientras que el efecto bactericida solo se observó en la canela frente a $S$. ser. typhimurium a 5 min y frente a $E$. coli O157:H7 a 10 min. Los extractos de molle, molle + sésamo y muña frente a $S$. aureus no presentaron ningún tipo de efecto. Esto puede relacionarse con lo descripto por diversos investigadores que han demostrado que se requieren altas concentraciones de principios activos de extractos vegetales 
Tabla 3. Evaluación del efecto bacteriostático/bactericida de los extractos vegetales (EV)

\begin{tabular}{|c|c|c|c|c|}
\hline \multirow{2}{*}{ Microorganismos + EV } & \multicolumn{4}{|c|}{ Tiempo (min) } \\
\hline & 0 & 2.5 & 5 & 10 \\
\hline S. aureus + molle & + & + & + & + \\
\hline S. aureus + canela & - & + & + & + \\
\hline S. aureus + muña & + & + & + & + \\
\hline S. aureus $+($ molle + sésamo $)$ & + & + & + & + \\
\hline S. aureus $+($ canela + sésamo $)$ & - & + & + & + \\
\hline S. flexneri $+($ canela + sésamo $)$ & - & + & + & + \\
\hline E. coli $(\mathrm{EAEC})+($ canela + sésamo $)$ & - & + & + & + \\
\hline E. coli $(\mathrm{ETEC})+($ canela + sésamo $)$ & - & + & + & + \\
\hline S. typhimurium + (canela + sésamo) & - & + & + & + \\
\hline S. typhimurium + canela & - & + & - & - \\
\hline S. enteritidis $+($ canela + sésamo $)$ & - & + & + & + \\
\hline S. enteritidis + canela & - & + & + & + \\
\hline E. coli $(\mathrm{EPEC})+($ canela + sésamo $)$ & - & + & + & + \\
\hline E. coli $(\mathrm{EPEC})+$ canela & - & + & + & + \\
\hline E. coli $(\mathrm{STEC})+($ canela + sésamo $)$ & - & + & + & + \\
\hline E. coli $(\mathrm{STEC})+$ canela & - & + & + & + \\
\hline E. coli $(\mathrm{EIEC})+($ canela + sésamo $)$ & - & + & + & + \\
\hline E. coli $(\mathrm{O} 157)+($ canela + sésamo $)$ & - & + & + & + \\
\hline E. coli $(\mathrm{O} 157)+$ canela & - & + & + & - \\
\hline
\end{tabular}

para lograr inhibir el crecimiento de microorganismos patógenos (Rodríguez Pava et al., 2017).

\section{Conclusiones}

En este trabajo se pudo observar que los extractos con mayor poder inhibitorio sobre enterobacterias patógenas fueron los obtenidos con solventes orgánicos con maceración, mientras que la extracción acuosa no mostró poder inhibitorio. Los extractos de sésamo y canela no mostraron efecto alguno frente a determinadas cepas, en cambio estos extractos combinados, frente a las mismas cepas, mostraron actividad inhibitoria, observándose un efecto sinérgico. La aparición de cepas resistentes a los antibióticos comerciales genera la necesidad de buscar otras alternativas para controlarlas. Tal es el caso del uso de plantas que contienen principios activos capaces de inhibir el crecimiento bacteriano. Por este motivo, los resultados obtenidos en el presente trabajo podrían ser tenidos en cuenta para futuros usos medicinales contra cepas bacterianas con particular interés en la Salud Pública.

\section{Agradecimientos}

El presente trabajo fue financiado con insumos propios de la cátedra de Microbiología
Aplicada, perteneciente a la carrera de Microbiología Clínica e Industrial, FCV-UNLP. El equipamiento utilizado fue proporcionado por el Centro de Investigación y Desarrollo en Criotecnología de Alimentos (CIDCA).

\section{Conflicto de intereses}

Todos los autores declaran que no existe conflicto de intereses.

\section{Bibliografía}

Amara AA. El-Masry MH, Bogdady HH. 2008. Plant crude extracts could be the solution: extracts showing antitumorigenic activity. Pakistan Journal of Pharmaceutical Sciences. 21(2):159-171.

Abadie R, Medina R, Ruiz L, Tresierra-Ayala A. 2014. Actividad antibacteriana de extractos vegetales frente a cepas intrahospitalarias, IquitosPerú. Revista ECIPerú. 11(1), 31-38.

doi: 10.33017/RevECIPeru2014.0005

Alegre A, Iannacone J, Carhuapoma M. 2017. Toxicity of aqueous, ethanolic and hexanic extracts of Annona muricata, Minthostachys mollis, Lupinus mutabilis, and Chenopodium quinoa against Tetranychus urticextractos and Chrysoperla externa. Chilean Journal of 
Agricultural \& Animal Sciences. 33(3):273-284. doi: 10.4067/s0719-389020017005000705

Arias JP, Silva GA, Figueroa IC, Fischer SG, Robles-Bermúdez A, Rodríguez-Maciel JC, Lagunes-Tejeda A. 2017. Actividad insecticida, repelente y antialimentaria del polvo y aceite esencial de frutos de Schinus molle L. para el control de Sitophilus zeamais (Motschulsky). Chilean Journal of Agricultural \& Animal Sciences. 33(2):93-104.

doi: 10.4067/ so719-38902017005000301

Bozin B, Mimica-Dukic N, Simin N, Anackov G. 2006. Characterization of the volatile composition of essential oils of some lamiaceae spices and the antimicrobial and antioxidant activities of the entire oils. Journal of Agricultural and Food Chemistry. 54(5):1822-1828.

doi: 10.1021/jfo51922u

Burt S. 2004. Essential oils: Their antibacterial properties and potential applications in foods - A review. International Journal of Food Microbiology. 94(3):223-253.

doi: 10.1016/j.ijfoodmicro.2004.03.022

Castro Montoya JM, Rangel-Peraza JG, PiñaHernández CJ, Mora-Rochín S, Rochín-Medina JJ. 2015. Actividad antioxidante de compuestos fenólicos en semillas de ajonjolí y su efecto sobre el crecimiento bacteriano. Revista Iberoamericana de Ciencias. Disponible en: www.reibci.org

Darré M, Valerga L, Araque LCO, Lemoine ML, Demkura PV, Vicente AR, Concellón A. 2017. Role of UV-B irradiation dose and intensity on color retention and antioxidant elicitation in broccoli florets (Brassica oleracea var. Italica). Postharvest biology and technology, 128, 76-82.

doi: 10.1016/j.postharvbio.2017.02.003

Deveci O, Sukan A, Tuzun N, Hames Kocabas EE. 2010. Chemical composition, repellent and antimicrobial activity of Schinus molle L. Journal of Medicinal Plants Research. 4(21):2211-2216. doi: 10.5897/JMPR10.326

García C, Martínez A, Ortega J, Castro F. 2010. Componentes químicos y su relación con las actividades biológicas de algunos extractos vegetales. QuímicaViva. Vol. 2(1): 12-21.

González Villa ÁA. 2004. Obtención de aceites esenciales y extractos etanólicos de plantas del Amazonas (Disertación doctoral, Universidad Nacional de Colombia-Sede Manizales). Disponible en: www.bdigital.unal.edu.co/1173

Henao Riveros SC. 2003. Actividad bactericida del ácido hipocloroso. Revista Facultad de Medicina, 51(3), 136-142.
Herrera Arias F, García-Rico RO. 2006. Evaluación in vitro del efecto bactericida de extractos acuosos de laurel, clavo, canela y tomillo sobre cinco cepas bacterianas patógenas de origen alimentario. Bistua: Revista de la Facultad de Ciencias Básicas, 4(2), 13-19.

Huamán S, Hurtado H, Kong V, León C, León D, Lister P, Miñano K, Orrego F, Santillán L. 2003. Estudio toxicológico y teratogénico del extracto metanólico de Cinnamomum zeylanicum (canela). Revista Horizonte Medico. Vol 3 No 1 y 2.

Pastrana Puche YI, Durango Villadiego AM, Acevedo Correa D. 2017. Efecto antimicrobiano del clavo y la canela sobre patógenos. Biotecnología en el Sector Agropecuario y Agroindustrial. 15(1):5665. doi: 10.18684/bsaa(15)56-65

Peredo-Luna HA, Palou-García E, López-Malo A. 2009. Aceites esenciales: métodos de extracción. Temas Selectos de Ingeniería de Alimentos. 3(1): 24-32. https://www.udlap.mx/WP/tsia/files/No3Vol-1/TSIA-3(1)-Peredo-Luna-et-al-2009.pdf

Ramírez-Albores JE. 2013. Distribución y abundancia de Musa velutina en un bosque nuboso, Ángeles de San Ramón, Alajuela, Costa Rica. Boletín de la Red Latinoamericana para el Estudio de Especies Invasoras. 3(1):16-22.

Rodríguez Pava CN, Zarate Sanabria AG, Sánchez Leal LC. 2017. Actividad antimicrobiana de cuatro variedades de plantas frente a patógenos de importancia clínica en Colombia. Nova, 15(27), 119-129.

Sánchez Miranda L. 2013. Determinación de compuestos funcionales en canela (Cinnamomum zeylanicum). Disponible en: https://tesis.ipn.mx/ bitstream/handle/123456789/25267/ S\%C3\%81NCHEZ\%2OMIRANDA\%2OLUISA.pdf? sequence $=1$ \&isAllowed $=\mathrm{y}$

Shiva Ramayoni CM. 2007. Estudio de la actividad antimicrobiana de extractos naturales y ácidos orgánicos. Posible alternativa a los antibióticos promotores de crecimiento. Tesis doctoral. Facultat de Veterinària. Universitat Autònoma de Barcelona. Disponible en: www.tdx.cat/bitstream/ handle $/ 10803 / 5606 /$ cmsride1.pdf?sequence $=1$

Wong YC, Ahmad-Mudzaqqir MY,Wan-Nurdiyana WA. 2014. Extraction of essential oil from cinnamon (Cinnamomum zeylanicum). Oriental Journal of Chemistry. 30(1):37-47.

doi: $10.13005 / \mathrm{ojc} / 300105$ 